\title{
The use of tracheostomy following major open cardiac surgery: a review of 64 cases
}

\author{
JOHNC. NICHOLLS 1 \\ From the Brompton Hospital, London, S.W.3
}

Sixty-four tracheostomies performed in the period September 1965 to August 1966 in patients undergoing major open-heart surgery are reviewed. The indications and complications are classified, and the high incidence of secondary infection is discussed briefly. Tracheal stenosis or dilatation occurred in six patients $(9 \cdot 4 \%)$ and the contributory factors are discussed in greater detail.

Tracheostomy is one of the oldest established procedures in surgical practice, but the indications for its use have undergone considerable changes, particularly in the last 25 years (Borman and Davidson, 1963). Its use is again under review (Lancet, 1967) and, as a result of the associated complications, many centres are using alternative methods, such as oro-tracheal and naso-tracheal intubation, even though they may have their own drawbacks (Tonkin and Harrison, 1966).

It is therefore pertinent to review the use of tracheostomy in relation to one of the more recent indications-that is, after major open cardiac surgery.

\section{MATERIAL AND METHODS}

All patients admitted to the intensive care unit at the Brompton Hospital from 1 September 1965 to 31 August 1966 were assessed. The minimum period of follow-up was four months to allow for the development of late complications. Of 179 patients submitted to cardiopulmonary bypass surgery 68 required a tracheostomy for intermittent positive pressure respiration.

The case records of 64 of these patients were examined; four were untraced. They consisted of a mixed population whose ages ranged from 6 to 63 years (average 34 years). Two patients had a second tracheostomy, and these are included as separate entities, as they were separated by a sufficient period of time and were, in any case, performed for different indications. There were 41 survivors $(65 \%)$.

TECHNIQUE AND MANAGEMENT All tracheostomies in this series were performed by a member of the sur-

\footnotetext{
${ }^{1}$ Present address : West Herts Hospital, Hemel Hempstead, Herts
}

gical team, and all followed a common technique. Under general anaesthesia the method of Björk $\Phi$ (1960), using a transverse skin incision and construct- $\frac{\partial}{0}$ ing an anterior tracheal wall flap stitched to the sub- $\underline{\mathbb{Q}}$ cutaneous tissues, was used. A plastic (Portex) cuffed $\overrightarrow{-}$ tracheostomy tube, of the standard pattern and appropriate size, was inserted and the cuff was inflated just ${ }^{\infty}$ sufficiently to make an airtight seal. A dry dressing only, or skin sutures, were used, and the tracheostomy tube was then connected to a sterile respirator of the intermittent positive pressure type.

During the period under review the nursing staff $\stackrel{\circ}{\circ}$ observed the following instructions for the manage- $\stackrel{\varrho}{a}$ ment of the tracheostomy:

The cuff was not released for the first 12 hours, and was then released for one minute every four hours following pharyngeal suction. It was then in-o flated again with just sufficient air to make an airtight seal.

Tracheal suction was applied hourly, or more frequently if necessary, via a sterile rubber catheter held by sterile forceps. A 'no-touch' technique was desir- 3 . able but was not always possible.

The wound was cleaned with chlorhexidine (1: 1,000) and sprayed with Polybactrin four-hourly and a dry dressing was applied. (This might have been 음 done more frequently if the dressing became moist.) $D$

A wound swab was taken and a trapped specimen of sputum was sent for culture the day following tracheostomy. These investigations were repeatedos every week unless more frequent results were re- $N$ quired. When pathogenic organisms were cultured the patients were isolated or, as circumstances demanded, $\omega$ were moved into a different ward in the company? of other patients with similar infecting organisms.e Treatment with the appropriate systemic antibiotics $\overparen{\mathbb{D}}$ was begun. The rooms were fumigated by a Hycolin $\stackrel{\odot}{+}$ spray for 24 hours before being brought back into 0 use.

The tracheostomy tube was only changed for specific indications. 


\section{RESULTS}

Tracheostomies were performed in $38 \%$ of all patients who underwent cardiopulmonary bypass. Forty-seven $(75 \%)$ were performed in the operating theatre, and the other 17 were performed in the intensive care unit.

INDICATIONS All tracheostomies except one were performed as elective procedures and these are divided into three groups (Table I). The only

\section{T A B L E I}

\begin{tabular}{|c|c|c|c|c|}
\hline Group & Indication & & $\begin{array}{l}\text { No. of } \\
\text { Cases }\end{array}$ & $\%$ \\
\hline $\begin{array}{l}1 \\
2 \\
3\end{array}$ & $\begin{array}{l}\text { Pre-operative decision } \\
\text { Operative decision } \ldots \\
\text { Post-operative complications }\end{array}$ & $\begin{array}{l}\cdots \\
\cdots \\
\cdots\end{array}$ & $\begin{array}{l}33 \\
10 \\
20\end{array}$ & $\begin{array}{l}52 \\
16 \\
32\end{array}$ \\
\hline
\end{tabular}

emergency tracheostomy was necessary for a patient in whom the endotracheal tube suddenly became blocked after 42 hours.

The indications in group 1 were all multiple valve replacements, total correction of Fallot's tetralogy, clinical evidence of pulmonary oedema, or a raised pulmonary vascular resistance. One patient in this group had sustained a cardiac arrest seven days pre-operatively and a tracheostomy was performed at that time.

In group 2 the following indications were used: a perfusion time longer than three hours, impaired cardiac function after total bypass, and suspected cerebral damage during operation due to anoxia or embolism. In one patient the sternum had to be left unsutured due to continued bleeding controllable only by packing.

In both these groups the tracheostomy was performed at the end of the operation before the patient left the theatre.

The post-operative complications (group 3) consisted of respiratory insufficiency after removal of the endotracheal tube, development of pulmonary oedema, development of a low output state, cerebral damage (unforeseen), and pulmonary emboli. Tracheostomy was performed if any of the above was expected to last for a time exceeding 48 hours after the beginning of the operation, this being accepted at that time as the maximum for which an endotracheal tube would be left safely in situ.

DURATION The mean period of intubation via the tracheostomy was $12 \cdot 1$ days (1-80 days), and for the survivors it was 14.7 days (2-80 days).

Sixty-one patients were artificially ventilated for the whole of these periods (except for the 24-hour trial period before the tube was removed). In the remaining three patients weaning off artificial ventilation was prolonged, and these patients had a tracheostomy with intermittent ventilator support lasting 18 out of 26,37 out of 63 , and 3 out of 5 days.

ENDOTRACHEAL INTUBATION This was performed in all patients, and the duration includes the time of operation. Forty-four patients had endotracheal intubation for 12 hours or less and one for 15 hours, being mainly those patients in groups 1 and 2.

In 14 patients the endotracheal tube was in place for between 24 and 48 hours. The remaining five patients had endotracheal intubation exceeding 48 hours, the longest being 73 hours' continuous intubation followed by re-intubation 9 hours later for a further 6 hours before tracheostomy was performed.

USE OF CURARE All patients were curarized for the period of operation, and its use was continued post-operatively for a period determined in consultation with the anaesthetist. Sedation was substituted as soon as the patients were able to tolerate the ventilator satisfactorily. In 20 patients no curare was required post-operatively. In the remaining 44 , curare was necessary for an average period of 32 hours (2-120 hours).

\section{COMPLICATIONS}

Infection In one patient infection was present before the tracheostomy was done and nine did not survive long enough for infection to become established. The patients fell into two groupsthose in whom the tracheostomy was performed in the theatre (38) and those in whom it was performed in the intensive care unit (16). In each case local, i.e., wound (if grown from the wound swab), and general (usually chest) infections were considered separately. Infection was determined by a positive culture and was thus not necessarily of clinical significance.

Of the intensive care unit patients local infection occurred in $14(87 \%)$ and general infection in all $(100 \%)$.

Six $(16 \%)$ of the theatre patients showed no evidence of either local or general infection, 32 (82\%) had a local infection, and 29 (74\%) had a general infection. The incidence of infection did not show any direct relationship to the duration of tracheostomy or previous endotracheal intubation. 
Pseudomonas pyocyanea, Escherichia coli, and Candida albicans were the commonest invading organisms.

Stenosis This occurred in three patients (4.7\%). In the first, the earliest evidence appeared 18 days after tracheostomy and was treated initially by repeated dilatations and eventually resection after 67 days. Death occurred at 94 days from a pyocyaneus septicaemia. The second patient developed a stricture 48 days post-operatively, which only required a single dilatation. Stenosis occurred in the third patient three months postoperatively and requires intermittent dilatation one year later.

Dilatation Tracheal dilatation also occurred in three patients three, four, and six weeks postoperatively, and in all insertion of a large orotracheal tube was required for a time to maintain ventilation until a larger tracheostomy tube was inserted. Anoxic cardiac arrest, with eventual recovery, occurred in one patient when a large enough tube was not immediately available, and it was thus impossible to maintain satisfactory ventilation.

Haemorrhage In two patients this was severe enough to require surgical intervention; in one bronchoscopy was necessary. Both episodes occurred on the seventh day and both patients were on anticoagulants. In three other patients there was some local bleeding which was controlled by conservative measures.

Miscellaneous The following complications also occurred (in some cases in association with those previously mentioned). Food and fluids leaked temporarily around the tracheostomy tube above the balloon in two patients. In four other patients, the tube was coughed up by one, blockage occurred at two days and required the tube to be changed in another, and a stitch abscess formed, resulting in a keloid scar, in the other two.

Thus 17 complications other than infection occurred in 12 patients (19\%). The complication was of a serious nature (stenosis, dilatation, and haemorrhage) in eight $(12.5 \%)$. It is impossible to attribute any deaths solely to the tracheostomy in such a group of seriously ill patients.

CLOSURE In only 16 of the 41 survivors was the time of closure of the wound recorded (closure implying disappearance of the air leak). This averaged $15 \cdot 7$ days (range 5-32), although in a further patient the wound was not fully healed two months later (following an 80-day tracheo stomy).

\section{DISCUSSION}

This series forms a useful group of patients who have had tracheostomies performed and who werw managed in a constant manner for a short period of time. They form their own control series for any one case, and the resulting complications can ${ }^{\omega}$ be considered by comparison with the uncomplio cated cases.

Two other similar series have been reported ino recent years (Robertson, 1964 ; Trimble and $\mathrm{Yao}_{2}$ 1966), but the series of McClelland (1965) and of Neville, Spinazzola, Scicchitano, and Langstore (1964) dealt with a wider selection of patients.

Robertson, in his series in 1963, gave an overalp incidence for tracheostomy of $32.4 \%$ in $389^{\circ}$ patients undergoing open-heart surgery, whicho compares with the $38 \%$ in the present series. Onlyo half of his patients were artificially ventilated, the main indication for tracheostomy being to allow efficient ventilation to continue. The other $50 \% \frac{\bar{s}}{-}$ were not ventilated artificially, but in a series on 50 patients reported by Trimble and Yao (1966) only one patient who had a tracheostomy was not artificially ventilated. This latter group is similaro to the present series, and it may be that the prophylactic tracheostomies performed by Robert son would not now be done.

In the present series, three cases were found in retrospect in which a tracheostomy may not haven been necessary, because the patients recovereof quickly, although this point is difficult to establish with any certainty ; in the rest it would seem tor have been essential. The indications for tracheo stomy after open-heart surgery are continuallyo changing and, as each new procedure becomes more firmly established, the necessity for a preo operative decision to perform a tracheostomy be comes less certain. Also, in the post-operativen period attempts are being made to avoid tracheo+ stomy by prolonged endotracheal intubation (Pracy, 1966 ; Lancet, 1967), although as recently as 1959 it was thought to be impossible to continue intermittent positive pressure respiration viac an endotracheal tube for more than 24 hours? (Cawthorne, Hewlett, and Ranger, 1959).

The incidence of complications in the presento series is higher than that previously reported,,$\vec{D}$ especially compared with Neville's series of mixecf post-surgical cases (Neville et al., 1964), but it is lower than in the random series of McClelland? 
(1965). The reasons for this are not clear but may be related to the longer mean duration of tracheostomy of 14.7 days, compared with 6.5 days (Robertson, 1964) and 6 days (Trimble and Yao, 1966). The only complications reported in the latter series were infection (not detailed) in seven patients; in the former series complications consisted of an obstructed airway in several patients, haemorrhage in two, and anoxia during suction in one.

The high incidence of infection in the present series is due to the inclusion of clinically nonsignificant infections, and possibly to the frequency with which specimens were taken. The only salient feature that emerged from the results was the markedly lower incidence of general infections resulting in the group submitted to tracheostomy in the theatre. The frequency was high despite all the precautions taken and, as in the patients described by Gotsman and Whitby (1964), was probably related to the hospital environment rather than to any other specific cause. Spalding (1966) was able to reduce lung infection by spraying the wound with Polybactrin every hour and using nystatin eight-hourly, and by the use of disposable polythene gloves when sucking out or touching the tracheostomy.

Of the other complications, haemorrhage in a certain number of patients appears to be unavoidable, but stenosis and dilatation deserve special attention.

The three patients who developed stenosis in this series showed no special common features (Table II) when compared with the series as a whole.
The incidence of stenosis $(4 \cdot 7 \%)$ was slightly lower than in Gibson's (1967) series. The three factors which he included in the possible aetiology, namely overinflation of the cuff leading to pressure necrosis, a piston-like action from the ventilator leading to shearing forces, and secondary infection, were not all present in our three cases. Four of his patients required surgical treatment, whereas surgery was necessary in only one of the above patients.

Tracheal dilatation has previously been reported in long-term cases (Lloyd and McClelland, 1964 ; Ringrose, 1965) and in our three patients certain common factors emerged. In two, leaking of food and fluids from the wound occurred after 9 and 18 days respectively; and both these eventually succumbed. The average age of the three patients (54 years) was higher than that of the whole series (34 years), as was the duration of the tracheostomy (55.5 days: 12.1 days), and all were massively infected at some stage. Two of the patients had endotracheal intubation for more than 24 hours, but the third was intubated only during operation. Two patients had prolonged periods of curarization, but the third required none (Table III). One patient was intolerant of the respirator for the first two weeks and there may have been considerable movement of the tracheostomy tube within the trachea. The numbers are too small for statistical analysis, but the above factors may be worthy of note.

Tracheal lesions are common after tracheostomy (Stiles, 1965), but their incidence may be lessened by the use of non-irritant plastic tubes instead of the red rubber tubes that were used formerly. This

T A B L E I I

\begin{tabular}{|c|c|c|c|c|c|c|c|}
\hline $\begin{array}{l}\text { Indication } \\
\text { (group) }^{1}\end{array}$ & $\underset{\text { (years) }}{\text { Age }}$ & $\begin{array}{c}\text { Duration } \\
\text { (days) }\end{array}$ & $\begin{array}{c}\text { Place } \\
\text { Performed }\end{array}$ & $\begin{array}{l}\text { Curare } \\
\text { (hours) }\end{array}$ & $\begin{array}{c}\text { Endotracheal } \\
\text { Intubation } \\
\text { (hours) }\end{array}$ & Infection & Outcome \\
\hline $\begin{array}{l}1 \\
2 \\
2\end{array}$ & $\begin{array}{r}6 \\
35 \\
38\end{array}$ & $\begin{array}{r}9 \\
11 \\
14\end{array}$ & $\begin{array}{l}\text { Theatre } \\
\text { Theatre } \\
\text { Theatre }\end{array}$ & $\begin{array}{r}4 \\
6 \\
24\end{array}$ & $\begin{array}{r}6 \\
10 \\
8\end{array}$ & $\begin{array}{l}\text { Local } \\
\text { Local and general } \\
\text { Local and general }\end{array}$ & $\begin{array}{l}\text { Survived } \\
\text { Survived } \\
\text { Died }\end{array}$ \\
\hline
\end{tabular}

${ }^{1}$ See Table I.

T A B L E I I I

\begin{tabular}{|c|c|c|c|c|c|c|c|c|}
\hline Indication & & $\begin{array}{c}\text { Age } \\
\text { (years) }\end{array}$ & $\begin{array}{c}\text { Duration } \\
\text { (days) }\end{array}$ & $\begin{array}{c}\text { Place } \\
\text { Performed }\end{array}$ & $\begin{array}{l}\text { Curare } \\
\text { (hours) }\end{array}$ & $\begin{array}{c}\text { Endo- } \\
\text { tracheal } \\
\text { Intubation } \\
\text { (hours) }\end{array}$ & Infection & Outcome \\
\hline $\begin{array}{l}\text { Pre-operative } \\
\text { Pre-operative arrest .. } \\
\text { Emergency } \quad . . \quad \ldots\end{array}$ & $\begin{array}{l}\cdots \\
\cdots\end{array}$ & $\begin{array}{l}46 \\
54 \\
61\end{array}$ & $\begin{array}{l}80 \\
23 \\
53\end{array}$ & $\begin{array}{l}\text { Theatre } \\
\text { Theatre } \\
\text { I.C.U. }\end{array}$ & $\begin{array}{r}48 \\
0 \\
64\end{array}$ & $\begin{array}{r}9 \\
35 \\
42\end{array}$ & $\begin{array}{l}\text { Multiple } \\
\text { Multiple } \\
\text { Pre-tracheostomy }\end{array}$ & $\begin{array}{l}\text { Survived } \\
\text { Died } \\
\text { Died }\end{array}$ \\
\hline
\end{tabular}


does not seem to have been the case when this series is compared with others. A prospective study of the histological changes found in tracheal mucosa following the use of these new tubes would be valuable.

I should like to thank the following: Mr. W. Williams, who originally suggested the subject for this review; Mr. M. Paneth. for his help and encouragement; Mr. W. P. Cleland and Mr. P. Gadhiali. for advice; and Lord Brock and Mr. O. S. Tubbs, for permission to study the patients under their care.

\section{REFERENCES}

Björk V. O. (1960). Partial resection of the only remaining lung with the aid of respirator treatment. J. thorac. cardiovasc. Surg., 39, 179.

Borman, J., and Davidson, J. T. (1963). A history of tracheostomy: si spiritum ducit vivit (Cicero). Brit. J. Anaesth., 35, 388.

Cawthorne, T., Hewlett, A. B., and Ranger, D. (1959). Discussion: tracheostomy today. Proc. roy. Soc. Med., 52, 403.

Gibson, P. (1967). Aetiology and repair of tracheal stenosis following tracheostomy and intermittent positive pressure respiration. Thorax, 22, 1 .

Gotsman, M. S., and Whitby, J. L. (1964). Respiratory infection following tracheostomy. Ibid., 19, 89.

Leading article (1967). Endotracheal intubation or tracheostomy. Lancet, 1, 258.

Lloyd, J. W., and McClelland, R. M. A. (1964). Tracheal dilatation. An unusual complication of tracheostomy. Ibid., 1, 83.
McClelland, R. M. A. (1965). Complications of tracheostomy. Brit. med. J., 2, 567.

Neville, W. E., Spinazzola, A., Scicchitano, L. P., and Langston, H. D. (1964). Tracheostomy and assisted ventilation. Use in respiratory insufficiency in the postsurgical patient. Arch. Surg., 89, 149.

Pracy, R. (1966). Respiratory units: intermittent positive respiration tracheostomy. Proc. roy. Soc. Med., 59, 35.

Ringrose, E. W. (1965). Tracheal dilatation following prolonged use of a cuffed endotracheal tube. Med. J. Aust., 1, 591.

Robertson, D. S. (1964). Tracheostomy and open heart surgery. Proc. roy. Soc. Med., 57, 855.

Spalding, J. M. K. (1966). Respiratory units: intermittent positive pressure respiration: tracheostomy. Ibid., 59, 29.

Stiles, P. J. (1965). Tracheal lesions after tracheostomy. Thorax, 20 517.

Tonkin, J. P., and Harrison, G. A. (1966). The effect on the larynx of prolonged endotracheal intubation. Med. J. Aust., 2, 581.

Trimble, A. S., and Yao, J. (1966). Tracheostomy: surgical technique and sequelae in fifty cardiovascular patients. $J$. thorac. cardiovasc. Surg., 51, 569 .

\section{ADDENDUM}

Since the period of review management of the tracheostomy has been modified in respect of releasing the cuff; this is now deflated for one minute in every hour. Also several patients have been ventilated via the endotracheal tube for periods longer than 48 hours without apparent added complications, although analysis has not yet been undertaken. 